\title{
LA ORGANIZACIÓN, EL SISTEMA Y SU DINÁMICA: UNA VERSIÓN DESDE NIKLAS LUHMANN
}

\section{RESUMEN}

RESUMEN

En este artículo se hará un esfuerzo teórico para enfatizar en las nuevas tendencias de la Teoría General de Sistemas sociales y una introducción al pensamiento sistémico desde su dinámica para develar la utilidad en la comprensión de las organizaciones y su entorno, teniendo en cuenta que esta teoría hoy está siendo aplicada en todos los campos del conocimiento, resaltando de manera especial los éxitos en cibernética, ecología, biología y computación

\section{Palabras Clave}

\section{Sistema}

Organizaciones

Dinámica de sistemas

\author{
Andrés Velásquez Contreras. ${ }^{1}$
}

\section{INTRODUCCIÓN}

\section{1}

todo y las partes, proponen identidades separadas, son la idea básica de sistema, más adelante se incluye la noción de relación para describir el todo en función de sus partes y viceversa. No es sino hasta Bertalanffy cuando se introduce el concepto de sistema dependiente de un entorno y el de retroalimentación, dando origen a la Teoría General de Sistemas. Teoría hoy con aplicaciones prácticamente en todos los campos del conocimiento, resaltando de manera especial los éxitos en cibernética, ecología, biología y computación. A continuación se hará un esfuerzo teórico para aterrizar las nuevas tendencias de la teoría de los sistemas sociales y una introducción al pensamiento sistémico desde su dinámica para develar la utilidad en la comprensión de las organizaciones y su entorno.

Se revisará principalmente la propuesta del Alemán Niklas Luhmann, algunos planteamientos de los autores Senge, O'Conner y McDermott, del biólogo Francisco Varela y del

\footnotetext{
1 Doctor en Filosofía y Letras por la Universidad Complutense de Madrid. Director Departamento de Sociología y Ciencias Políticas y de Administración de la Universidad Santiago. Profesor e investigador invitado en varias Universidades Iberoamericanas (Argentina, México, Chile, Perú, Colombia, El Salvador). GPyMES Universidad EAN.
} 
premio Novel de economía Douglass North. Configurando una amalgama de disciplinas y puntos de vista sobre la distinción sistema aplicada al análisis de las organizaciones y su dinámica.

La motivación para escribir este artículo radica en la visita y comentarios que realizó el profesor español Juan Luis Pintos de CeaNaharro que acompañó al grupo GPyMES en sus acostumbradas tertulias de los martes en la Universidad EAN. En una conversación muy amena y rigurosa, realizó un viaje intelectual por la obra de Luhmann, con énfasis en el papel de los medios de información como creadores de imaginarios y realidad. Se logro evidenciar que la sociología teórica hoy más que nunca se ha consolidado tanto desde el punto de vista filosófico como práctico, cuestión casi imposible de lograr, solo una pluma brillante como la de Luhmann lo alcanzaría.

\section{EL OBSERVADOR DEL SISTEMA}

¿Se requiere de un observador para que el sistema exista o éste es independiente de él? Luhmann inicia su desarrollo teórico afirmando

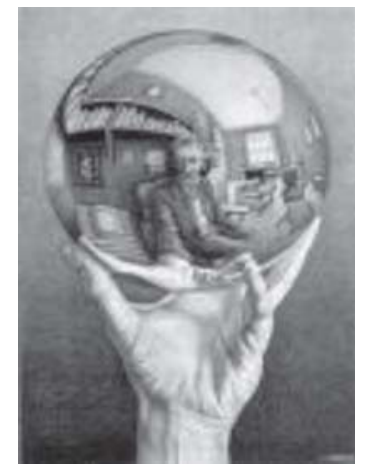

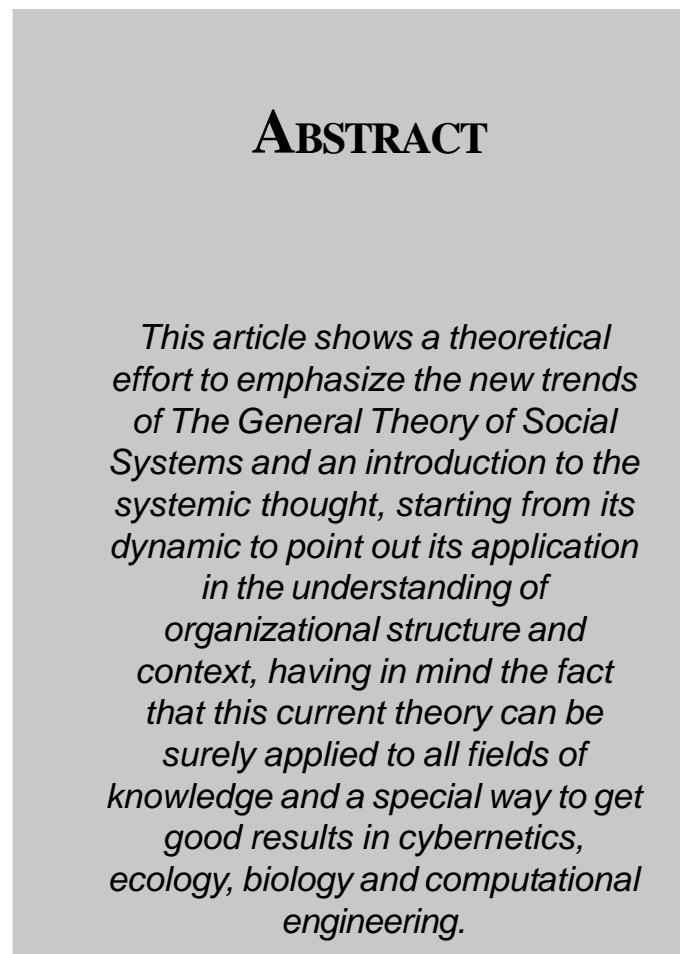

KEY WORDS

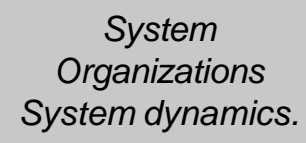

${ }^{2}$ Citado por KROGH, Georg von, ICHIJO, Kazuo y NONAKA, Ikujiro. (2000). Facilitar la creación de conocimiento. OXFORD University Press. México. Pg. 6.

${ }^{3}$ LLINAS, Rodolfo. El cerebro y el mito del yo: El papel de las neuronas en el pensamiento y el comportamiento humanos. Editorial Norma, Bogotá. 2005.

4 Salazar, Diego Rodrigo. Distinciones y Comunicaciones. Hacia una teoría social hermenéutica y constructivista en arqueología. Cinta de Moebio No.2. Diciembre de 1997. Facultad de Ciencias Sociales. Universidad de Chile. http:// www.moebio.uchile.cl/02/frprin04.htm. 
El conocimiento está a menudo en el ojo del observador, y se da significado al concepto según se le use (Wittgestein, 1958)2. El observador crea conocimiento cuando éste lo hace explícito, lo comparte y aplica en un dominio de acción o contexto propicio. Una perspectiva constructivista, en la cual el observador elabora la realidad desde patrones de actuación fijos ${ }^{3}$, las experiencias previas y los procesos de pensamiento para comprender y actuar en la sociedad, contribuye a comprender el origen de las descripciones y las posturas científicas, en palabras de North (2007:51), nos conduce a "El descubrimiento de patrones donde no los hay es coherente con el esfuerzo ubicuo de los seres humanos por hacer que descripciones, teorías o dogmas expliquen el mundo que los rodea aun en ausencia de una explicación 'científica'. En efecto, tal vez sea un rasgo superior de supervivencia contar con alguna explicación en lugar de ninguna para los problemas que enfrentamos."Gregory Bateson es mas fuerte en sus apreciaciones, "sostiene que en última instancia sólo podemos percibir lo que ya conocemos: y el conocimiento está en la mente. Al igual que Von Foerster, Bateson señala que la percepción es una síntesis que se halla en la mente. La realidad es construida en la medida que realizamos distinciones.

Desde esta perspectiva, la realidad que percibimos es una construcción a partir de los propios esquemas de distinción que manejamos como observadores y no esa entidad objetiva y absoluta que podíamos aprehender mediante los sentidos (empirismo) o la razón (racionalismo)" ${ }^{\prime 4}$. Figura 1.

Figura No. 1. Cuadros negros ${ }^{5}$

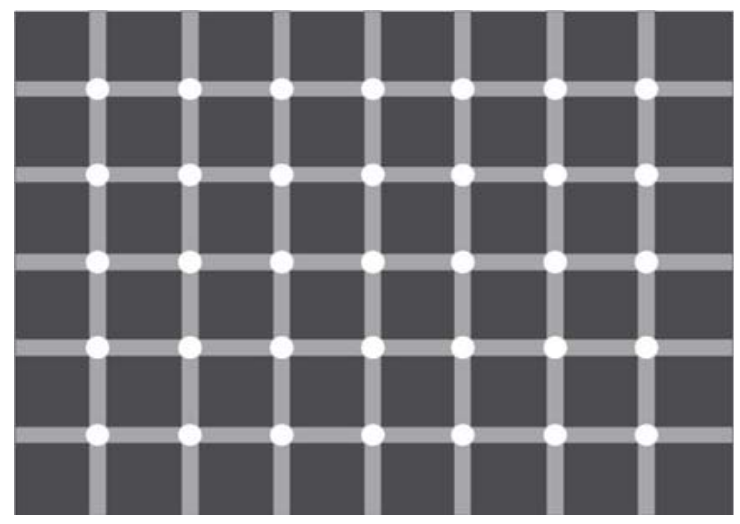

La discusión sobre reformular conceptos, definiciones o nuevas distinciones, en este caso sistema y organización debe centrase en su principal función, dar identidad para posibilitar la diferencia y por tanto mejorar la percepción del observador y de su colega. Lograr concretar esta función implica rigurosidad, lógica formal, experimentación, contexto o referentes teóricos complementarios o discentes, se trata de ser pragmáticos en el sentido lingüístico, es decir, conceder significado en contexto. El profesor Pintos, lo recrea de la siguiente manera:

\footnotetext{
5 http://www.epsilones.com/paginas/i-figurasimp.html\#figimp-ambiguedadanimal
} 
Observar es, como repetimos siempre, generar una diferencia con la ayuda de una distinción, que no deja fuera con ello nada distinguible. En el medio verdad el sistema comunicativo sociedad constituye el mundo como una totalidad, que incluye todo lo que es observable y hasta el observador mismo. Con ese objetivo se establece en el mundo un sistema observador que se observa a sí mismo, que tiene disponibilidad sobre el valor reflexivo de la falsedad ( $y$ tiene disponibilidad también sobre lo observable, lo empírico y lo fáctico, evidentemente) y de ese modo puede marcar algo cuyo correlato no puede ser atribuido al mundo. El refinamiento de esta distinción verdadero/falso consiste precisamente en que es utilizable operativamente, por tanto que funciona empíricamente (lingüísticamente) en el mundo, pero que al mismo tiempo, en cuanto distinción, no se proyecta sobre el mundo. La distinción no presupone ningún mundo correlativo para la falsedad. El mundo excluye e incluye la falsedad, y esto es también válido en el uso de los códigos sobre sí mismos, en la investigación de la verdad y también en la observación de la propia paradoja ${ }^{6}$.

La discusión y la decisión que debe realizar el lector está en la objetivización del sistema; el cuerpo humano, la célula y la empresa son en sí mismos sistemas o ellos son sistemas gracias a la distinción de un observador que intenta comprobar, validar, falsear o describir patrones que a su vez están en su mente y pueden resultar una ilusión como lo comprueba el experimento de Feldman (North, 2007:51).

\section{ORGANIZACIÓN Y SISTEMA}

La concepción actual de organización empresarial se redefine a partir de los cambios que caracterizan el nuevo siglo; las organizaciones basadas en conocimiento, en tecnología de la información y en mercados globales, para operar en cluster del conocimiento. La organización es pues un sistema orgánico inmerso en un medio hostil con el que se intercambia energía, materia información y dinero, es decir, que la organización es un sistema socio-técnico abierto, el cuál posee, relaciones de entradas (insumos), salidas (productos) y retroalimentación o ciclos de retorno para modificar el propio sistema, en estructura, operación, función o propósito, permitiendo su permanencia en el tiempo, además de procesos internos de readaptación, construcción y autoreparación, que le permiten interrelacionarse adecuadamente con un entorno.

Un gerente orienta y dirige acciones, las personas según sus capacidades, motivaciones y entendimiento ejecutan las instrucciones, las cuales se convierten en rutinas y procesos, estos modos de actuación se incorporan como modelos mentales, que en algún momento se convierten en modelos compartidos y quizás en cultura, este ciclo genera reglas y una forma particular de concretar procesos con los propios

\footnotetext{
6 Pintos, Juan Luis. La nueva plausibilidad: la observación de segundo orden en Niklas Luhmann. Consultado 20 de septiembre de 2007. http://web.usc.es/ jlpintos/articulos/
} 
mecanismo instituidos, se trata de una estructuración de un sistema social enactivo, es decir una representación de la acción que posibilita la emergencia de micro-mundos y la cognición individual y organizacional. Este sistema social gestiona conocimiento y luego lo comparte con otras organizaciones e instituciones.

La organización es antitética al caos. Cuando un observador es capaz de hacer una distinción es porque su modelo mental permite comprender la complejidad asociada al evento o a la configuración que pretende estudiar, reconoce en ello un cierto orden, lógica y estructura. Respecto del concepto de organizaciones sociales, además del orden el propósito es importante, ya que los individuos se agrupan por muy distintas razones, desde la familia, la iglesia, el ejército o las grandes corporaciones. La organización es un sistema de roles y relacionamientos con una finalidad, la cual se alcanza mediante procesos coordinados en una estructura que propicia la emergencia de atributos necesarios para actuar en un entorno.

Los roles son designaciones o compromisos, llevados a la acción por personas, las relaciones son producto de la comunicación, del dialogo o de una conversación, los procesos y su estructura responden a acuerdos implícitos o explícitos de operación. Entonces, es posible entender una organización como una expresión o fenómeno lingüístico. Lo cual reduce la administración a un acto de comunicación. (Flores, 1996b:11)

El concepto de organización ${ }^{7}$ se refiere al establecimiento y agrupación de actividades y recursos necesarios que interactúan entre sí a través de una coordinación horizontal y vertical para el cumplimiento de los objetivos contemplados en la estructura de la empresa. Para Morin "la organización es la disposición de relaciones entre componentes o individuos que produce una unidad compleja, dotado de cualidades desconocidas en el nivel de los componentes o individuos... Asegura solidaridad y solidez relativa a estas uniones, una cierta posibilidad de duración a pesar de las perturbaciones aleatorias. La organización, pues, transforma, produce, reúne, mantiene"8. Dicho de otra forma, la organización es el conjunto de interrelaciones entre sus elementos constitutivos, es decir los roles o cargos, las cuales conforman una red cerrada que posee una identidad propia ${ }^{9}$. Las organizaciones son entonces, formaciones sociales específicas en el tiempo y el espacio, desarrolladas por la sociedad como formas de articulación para resolver problemas concretos y que obran bajo propósitos específicos. (Ocampo, 2007).

Luhmann (1997:XXIII) define la organización como un sistema compuesto por complejos decisionales, cuestiona la congruencia entre decisión y acción, afirmando que decidir es probar las alternativas, ignorando así el proceso de diseño del observador, resulta conveniente entender las decisiones más bien como diseños. Efectivamente no toda acción humana o empresarial requiere de un diseño formal, mínimo implica una toma de alternativa.

En síntesis, la organización es una unidad compleja y social, con elementos que la componen y le dan identidad, constituida para, por y con el entorno, comprendida y estudiada como fenómeno económico emergente y como sistema abierto con clausura. De allí se desprende su identidad, dinámica y posibilidad de cambio.

\footnotetext{
7 SCHVARSTEIN, Leonardo. Psicología social de las organizaciones. Paidos, Buenos Aires, 2001.

8 MORIN, Edgar. El Método tomo I, «La naturaleza de la naturaleza», Catedra, Madrid 1981.

${ }^{9}$ REYES, Alfonso. Notas de clase curso Diagnóstico Organizacional. Bogotá: Universidad de los Andes, Maestría Ingeniería Industrial, Primer semestre 2005.
} 


\section{LOS SISTEMAS}

En principio, sistema es un conjunto de entidades mutuamente relacionadas que pretenden un objetivo común. Otra perspectiva propone que un sistemas es una distinción que hace un observador, él estable los limites, identifica la estructura, los componentes objeto de estudio y los fenómenos circulares de causalidad y retroalimentación, es decir, las causas y efectos que constantemente se refuerzan o equilibran. El sistema está en el ojo del observador, es decir, el lector o el analista configuran el sistema que observan, figura 2 .

Figura 2. Galería de cuadros (Escher)

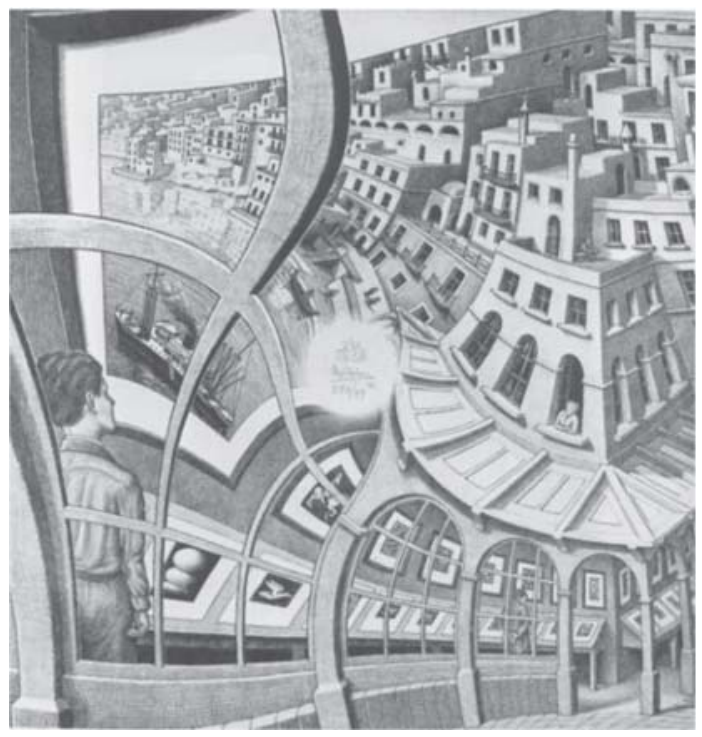

La propuesta de la Teoría General de Sistemas de Bertalanfy (1976), la cibernética de Weiner
(1985) y Ashby (1977), el Modelo de Sistema Viable de Beer (1988), la cibernética de segundo orden de Von Foester (1996), la dinámica de Forrester (1981), la $\vee$ disciplina Senge (1990 y 2000), los sistemas emergentes de Johnson (2001) y la sistémica social de Luhmann (1998), constituyen esquemas de análisis y diseño organizacional de carácter holístico que combinan la identificación de los elementos, las relaciones entre si y las propiedades emergentes en la unidad sistema/entorno.

En el sentido tradicional un sistema es un conjunto dinámico de elementos y partes entre las cuales existe funcionalidad, se percibe como un "todo complejo" que esta conformado por diversas combinaciones de elementos y partes. Así el principio de la cibernética "sólo la complejidad absorbe complejidad" y el pensamiento complejo que propone Morin (1994), se integran fortaleciendo la teoría de sistemas.

El ejemplo típico es cualquier organismo ya que este está conformado por órganos y conexiones que funcionan mediante una dinámica compleja que hace posible que el ser vivo sea interpretado como un sistema; combinación de partes (unidades) mutuamente relacionadas entre si (complejo). Sin embargo esta aproximación descuida la importancia de la sinapsis e interconexión con el entorno.

El profesor Pintos describe el proceso histórico de la distinción sistema: 
"Otra clarificación inicial consiste en rechazar la idea ontológica de sistema, de la que han surgido los conceptos de organismo y de máquina. El sistema era una ordenación de partes para integrar un todo; del orden interno de las partes surge el todo que es algo más que la mera suma de las partes. Se problematizó el orden interno del sistema, su racionalidad, mientras que el entorno se ignoraba o era considerado sólo como algo englobante.

El proceso por el que la actual teoría de sistemas se ha ido separando de esa concepción se ha planteado secuencialmente. Primero se sustituye la diferencia tradicional entre todo y parte por la diferencia entre sistema y entorno. Sigue una generalización del procedimiento diferenciador por el que se van estableciendo nuevas diferencias de sistema y entorno en el interior del sistema; el sistema global se utiliza como entorno de los sistemas parciales. Finalmente, desarrollando la idea de sistemas abiertos se ha llegado a la teoría de los sistemas autorreferenciales

(Luhmann, 1984, 22-24/30-31).

Los sistemas sirven para una reducción de la complejidad, y precisamente a través de la estabilización de la diferencia dentro/fuera. [...] Los sistemas sociales son sistemas identificables por el sentido [...] Sentido es una determinada estrategia de comportamientos selectivos bajo condiciones de elevada complejidad (Luhmann, 1971a, 11-12)

Se plantea así el tema más recurrente en la perspectiva luhmaniana de teoría de los sistemas que es el de la complejidad con su correlato del sentido como estrategia de reducción de la complejidad. De ahí que podamos llegar a una primera definición de la sociedad como aquel sistema social que institucionaliza las reducciones últimas y fundamentales [...], aquel sistema social cuyas estructuras son decisivas para mantener el alto nivel de complejidad de la humanidad ('der Mensch'), de tal forma que se pueda vivir y actuar con sentido" (Luhmann, 1971a, 16-17). Pues, frente a las sociedades anteriores a la modernidad en las que el sentido era proporcionado desde un todo compacto, actualmente los procesos de sentido están fragmentados en subsistemas (verdad, derecho, amor, etc.), lo cual viene a significar que cada sentido determinado es una elección entre otras muchas posibilidades, "cada sí implica varios noes" (ibid., 22)."10

El neo-institucionalismo plantea una sociedad económica compleja, en la cual las instituciones regulan y reducen la incertidumbre, en ese sentido North nos hace saber: "En esencia, cuanto mas rica es la estructura de artefactos [instituciones], mayor es la reducción de la incertidumbre cuando se trata de tomar decisiones en un momento determinado. Con el paso del tiempo, cuanto más rico es el contexto cultural desde el punto de vista de la provisión de una experimentación múltiple y una competencia creativa, la supervivencia exitosa de la sociedad es más probable... Cuanto más rica es la estructura artefactual, más amplia la gama de decisiones de rutina que pueden tomarse. En sustancia, el juego se ha estructurado con el fin de aliviar al individuo de la incertidumbre en la toma de decisiones. En contraste, un medio ambiente en desorden es aquel en que las rutinas se han desmoronado y la incertidumbre ha aumentado. (North 2007:63/64)

\footnotetext{
${ }^{10}$ El metacódigo «relevancia/opacidad» en la construcción sistémica de las realidades. Consultado 20 de septiembre de 2007. http://web.usc.es/ jlpintos/articulos/.
} 
Finalmente, para Luhmann (1998: 37) el concepto de sistema designa un objeto y asume con ello la responsabilidad de probar sus afirmaciones en la realidad. De esa manera puntualiza la posibilidad de analizar sistemas reales en el mundo real. "Es decir, un sistema es una forma con propiedades que le distinguen como unidad de una diferencia; una forma que consiste en la distinción de algo (el sistema) respecto del resto (el entorno) como la distinción de algo respecto a su contexto. Sistema y entorno, en cuanto constituyen las dos partes de una forma, pueden sin duda existir separadamente, pero no pueden existir, respectivamente, uno sin el otro. La unidad de la forma permanece presupuesta como diferencia, pero la diferencia no es fundamento de las operaciones. Las operaciones sólo son posibles como operaciones de un sistema".

Cada sistema da origen a sus propiedades emergentes, surgen únicamente cuando un sistema está en funcionamiento por encima de las partes que lo compongan, como por ejemplo el ojo humano, este no puede ver si no esta conectado con sistema, ya que si uno lo pusiera encima de una mesa no funcionaría. Los sistemas también constan de una estabilidad, y esta depende de muchos factores, como el tamaño, la cantidad y diversidad de los subsistemas que abarque y el tipo de conectividad que exista entre ellos.

\section{ORganismos O LOS SISTEMAS VIVOS}

La propuesta de la biología moderna está fundada en los conceptos de patrón de vida, estructura disipativa y la cognición. El primero es la autopoiesis: se refiere a los sistemas que reproducen todas las unidades elementales de los que se componen a través de una red y con ello se delimitan de un entorno. La característica de una red viviente es que se reproduce a sí misma continuamente. Por tanto, "el ser y el hacer de (los sistemas vivos) son inseparables y éste es su modo específico de organización". La cognición -el proceso de vida- está inextricablemente unida a la autopoiesis. La cognición implica siempre la existencia de una red autopoiética. La estructura disipativa involucra puntos de inestabilidad en los que pueden surgir nuevas estructuras y formas de orden. Entonces los criterios clave de un sistema vivo son:

- Patrón de organización: la configuración de las relaciones que determina las características esenciales del sistema.

- Estructura: la corporeización física del patrón de organización del sistema

- Proceso vital: la actividad involucrada en la continua corporeización física del patrón de organización del sistema (Capra, 2006:175)

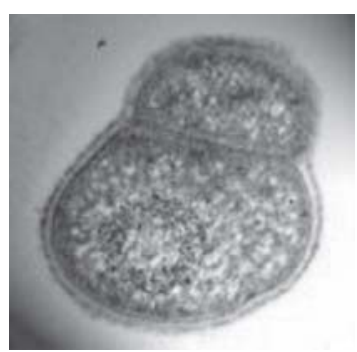

Los organismos vivos son sistemas autogestionados: presentan auto-regulación quiere decir que los cambios y los imprevistos en el entorno son equiparados por el sistema y éste acomoda sus parámetros y mecanismos evolucionando.

Capra (2006), Varela (2002) y Maturana (1987), han trabajo profundamente estos conceptos en sus libros: La trama de la vida, El fenómeno de la vida y El árbol del conocimiento, respectivamente. El ejemplo de la célula bacterial y sus mecanismos de vida sustentan los conceptos mencionados más atrás. 
Un sistema social, es distinto de su entorno y operacionalmente cerrado, o sea, capaz de producir por sí mismo, elementos propios y estructuras propias. Esta definición general es necesaria pero insuficiente para observar y analizar los sistemas sociales. Para Luhmann (1998) existen básicamente tres sistemas (vivos, psíquicos, sociales) que se diferencian por su propio tipo de operación y el modo en que reducen la complejidad. Es por este motivo que Luhmann engloba la sociedad en un conjunto de comunicaciones, comprendiendo al ser humano como un sistema más, logrando establecer el entorno/sistema social. Figura 3.

FIGURA 3

Tomado de (Luhmann; 1998:27)

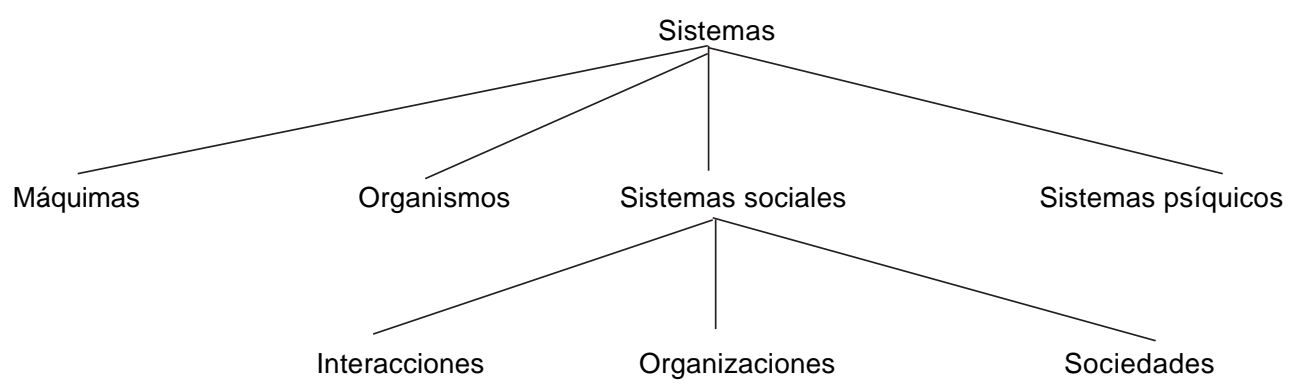

"La elaboración de una teoría de sistemas autorreferenciales, que incluye la teoría sistema/entorno, hace necesaria una nueva diferencia directriz, por tanto un nuevo paradigma. Se ofrece aquí la diferencia entre identidad y diferencia, ya que la auto-rreferencia sólo puede realizarse en las operaciones actuantes del sistema si por sí misma identifica a un sí mismo (como elemento, como proceso o como sistema), y lo identifica como diferente frente a un otro. Los sistemas se las tienen que arreglar con la diferencia entre identidad y diferencia cuando se reproducen como sistemas auto-rreterenciales." (Luhmann; 1998: 34). De lo cual se puede deducir que las organizaciones racionalmente creadas por empresarios, con relaciones múltiples, pueden y están conformadas como sistema/entorno, lo que hoy se llama capacidades y stakeholders.
En Luhmann (1997) Organización y Decisión. Autopoiesis, acción y entendimiento comunicativo, en la nota a la versión en español de Darío Rodríguez Mansilla se lee, que aquí se despliegan las bases para enfrentar los sistemas organizacionales como sistemas compuestos por decisiones, que generan sus propios elementos y que definen sus relaciones con su entorno -reducen complejidad-. Más adelante Luhmann (1997:3) afirma: "organización es la realización de la autoridad o de la producción... la organización se conceptualiza en su unidad mediante un esquema racional, y su progreso se evalúa de acuerdo con la medida en que se alcanza un ideal. En términos modernos la organización no se diferencia de la sociedad ni en los ámbitos sociales...". 
En detalle las organizaciones son complejas, identificadas por Luhmann (1997:14) como sistema organizacionales de relaciones entre decisiones selectivas crecientes, "Se puede caracterizar un sistema como complejo cuando es tan grande, es decir, cuando incluye tantos elementos, que ya no puede ser combinado cada elemento con cada uno de los otros, sino que las relaciones deben producirse selectivamente."

La racionalidad, las decisiones y la complejidad son expresiones de las organizaciones como sistemas: "Los criterios clásicos de racionalidad se referían a la relación entre medio y fin y definían en esa perspectiva sus exigencias de optimización. La teoría de la organización se ha atenido hasta el momento predominantemente a esta idea. En esta perspectiva se ha descubierto entonces, la complejidad, la cual ha sido conceptualizada como dificultad del decidir. La complejidad impone frente a barreras de la capacidad cognitiva y frente a límites de costos de tiempo, la limitación de las exigencias de racionalidad -pero siempre en vistas a la relación entre fines y medios." Luhmann (1997:21). En el siguiente párrafo Luhmann no deja lugar a duda que las organizaciones son complejas, racionales y sistemas:

"Todo esfuerzo de racionalización implica por lo tanto un aumento del número de decisiones y con esto un aumento del tamaño y complejidad del sistema -al menos en el caso en que se conserve la concepción de que una organización debería componerse de decisiones como elementos y no debería derivar en dirección al solo comportamiento. La racionalización es un proceso de crecimiento. Bajo condiciones adecuadas pueden ser traspasadas al computador cantidades inmensas de decisiones. Esto permite tamaños de sistemas antes inimaginables, pero significa, al mismo tiempo, un crecimiento desequilibrado en dirección a procesos de decisión rutinizables." Luhmann (1997:27), entonces, "se puede comprender que un sistema organizacional establece mecanismos de amplificación que hacen más probable (en comparación con las esperanzas casuales o en comparación con el entorno) que se decidirá y que se decidirá interdependientemente". Luhmann (1997:44).

Concluye Luhmann (1997:45): "Las organizaciones son en eso sistemas sociales que se permiten tratar al comportamiento humano tal como si fuera un decidir. La realidad social del decidir en organizaciones es interpretada por consiguiente como la sola aceptación o suposición o sugestión de los participantes en el sistema."

Es cierto que los sistemas se construyen, sea conceptualmente o realmente, mediante identidad y diferencia, en este caso visualizando entorno y sistema, como lo manifiesta Luhmann (1997:105): "los sistemas sólo pueden constituirse por diferenciación, distinguiéndose así de su entorno, lo cual es válido no sólo para sus estructuras, sino también para los elementos mismos que los conforman.". Así como los sistemas se diferencian y se distinguen de su entorno, al igual que sus estructuras, es posible que un observador haga lo mismo respecto de una organización, identificando además las operaciones internas para simplificar la complejidad. Para lo cual Luhmann se apoya en el concepto de autopoiesis: 
"Un sistema autopoiético puede representarse entonces como algo

"autónomo", sobre la base de una "organización cerrada" de

reproducción auto-referencial. Clausura y auto-referencia se relacionan

en un nivel formado por la síntesis de elementos, y no niegan en modo alguno la dependencia respecto al entorno a otros niveles.

Queda claro, no obstante, que en el ámbito de los sistemas

autopoiéticos, la clausura circular interna es condición sine qua non

para la continuidad de la auto-reproducción del sistema y que el

cese de la misma significaría la muerte...Un sistema produce los

elementos que lo constituyen, con ayuda de los elementos que lo

constituyen. Ésta es una exigencia del punto de vista según el cual se

sintetizan los elementos y se los utiliza como unidades para la reproducción autorreferencial.", Luhmann (1997:106/110).

Luhmann (1998:33), para desarrollar la teoría de sistemas autorreferentes sostiene que la diferenciación solo puede llevarse a cabo mediante autorreferencia; es decir, los sistemas sólo pueden referirse a sí mismos en la constitución de sus elementos y operaciones elementales. Así se puede hablar de inclusión y exclusión, es decir, identificar una frontera lo cual nos lleva a diferenciar y caracterizar el sistema. No es sino, una distinción que hace un observador en un campo acción determinado, estableciendo una limitación, y así separando el entorno del sistema, pero también dándole unidad.

La sociedad será comprendida primero que nada, como un sistema de códigos autogenerados y en cambio constante. En el caso de los sistemas sociales, esto sucede mediante la comunicación. La comunicación tiene todas las propiedades necesarias para la autopoiesis del sistema: es una operación genuinamente social. Es una operación social porque presupone el concurso de un gran número de sistemas de conciencia, pero precisamente por eso, como unidad, no puede ser imputada a ninguna conciencia sola. Es social porque de ningún modo puede ser producida una conciencia común colectiva, es decir, no se puede llegar al consenso en el sentido de un acuerdo completo; y sin embargo, la comunicación funciona

El concepto de auto-observación no presupone que en un sistema exista, de cuando en cuando, sólo una posibilidad de la autoobservación. Muchas comunicaciones pueden ser efectuadas y auto-observadas simultáneamente.

Es necesario aclarar que los textos de Luhmann requieren varias lecturas, antes de anticiparnos a sacar conclusiones, pero he colocado los párrafos textualmente de las traducciones al español que tengo a la mano, para que el lector por su propia lectura apruebe o desapruebe mis afirmaciones, sobre si los sistemas son realidades concretas, meras distinciones o instrumentos cognitivos. Sin embargo, la conclusión es que Luhmman entiende a las organizaciones como sistemas reales, incluso habla de empresarios y gerentes como creadores de organizaciones, en el contexto de los sistemas sociales. 


\section{SISTEMA Y ENTORNO}

El paradigma central de la nueva teoría de sistemas se llama sistema/entorno. Entonces el concepto de función y el análisis funcional no se refiere al sistema, sino a la relación entre sistema y entorno. El concepto de entorno no debe entenderse como una categoría marginal, debido a que es un estado de cosas relativas al sistema. Cada sistema se delimita a si mismo frente a su entorno, por ello el entorno de cada sistema es distinto. Por consiguiente también la unidad del entorno esta constituida por el sistema. El entorno es solo un correlato negativo del sistema. No es una unidad capas de realizar operaciones, no puede percibir al sistema, no lo puede manejar, ni pude influir sobre el, Luhmann (1998:172).

El entorno contiene una multiplicidad de sistemas complejos que pueden entablar relaciones con otros sistemas que conforman el entorno de los primeros, ya que para el sistema que conforma el entorno del sistema, el sistema mismo es parte del entorno y en este sentido objeto de posibles operaciones. En entornos de conocimiento la incertidumbre disminuye cuando el conocimiento aumenta y se comparte, preferiblemente en las cadenas de abastecimiento o en cluster instituidos o emergentes.

Los sistemas están estructuralmente orientados al entorno y sin él, no podrían existir. Sistema y entorno mantienen una unidad indisoluble. Por tanto, no se trata de un contacto ocasional ni tampoco de una mera adaptación. Los sistemas se constituyen y se mantienen mediante la creación y la observación de la diferencia con el entorno. Sin la diferencia respecto del entorno no habría auto-referencia, ya que la diferencia es la premisa para la función de todas las operaciones auto referenciales. De esta manera, la conservación de los límites es la conservación del sistema.
La diferencia entre sistema y entorno obliga, como paradigma de la teoría de sistemas, a sustituir la diferencia del todo y las partes por una teoría de la diferenciación de los sistemas. La diferenciación de los sistemas es, simplemente, la repetición de la formación de sistemas dentro de los sistemas. Asimismo, dentro de éstos se pueden encontrar diferenciaciones de diferencias adicionales de sistema/entorno. Con ello, el sistema global adquiere la función de "entorno interno" para los sistemas parciales, el cual, sin embargo, es específico de cada uno de ellos. La diferencia de sistema/entorno se verá duplicada: el sistema global se multiplica en una pluralidad de diferencias sistema/entorno. Cada diferencia de sistema parcial/entorno interno se constituye en un sistema global, aunque de perspectiva distinta. De allí que el sistema de diferenciación sea un procedimiento de aumento de la complejidad con consecuencias considerables para aquella unidad que todavía pudiera observarse del sistema global (Luhmann, 1998:42).

El sistema puede lograr una determinada primacía en la forma de su unidad, mediante algo como la igualdad de los sistemas parciales, como una simple serie, como una orden de rangos, como diferencia entre centro y periferia, como diferenciación de funciones en los sistemas. Con ello, las formas de diferenciación de los sistemas de más altas pretensiones y por lo tanto los más improbables son, a la vez, adquisiciones centrales evolutivas que, al llevarse a cabo, logran estabilizar a los sistemas en un nivel muy alto de complejidad.

Desde hace algunos años se presentan tendencias que describen la diferenciación del sistema como "jerarquía". Ello no significa la ordenación de las instancias ni tampoco una cadena de instrucciones de arriba hacia abajo. En este contexto jerarquía significa más bien, que los sistemas parciales pueden, al mismo 
tiempo, diferenciar sistemas parciales y originar, de esta manera, una relación transitiva del estar incluido en el estar incluido. Las ventajas racionales de la jerarquización dependen, sobre todo, de que dentro de los sistemas parciales se puedan formar sistemas adicionales. Pero esta suposición solamente puede valer en gran medida para organizaciones, ya que éstas se las puede asegurar mediante reglas formales.

\section{CoMPleJIDAD LUHMANNIANA}

¿Cuántas veces usted se ha sorprendido de la complejidad de un ejercicio, una situación o un problema? Pero quizás es más sorprendente la simplicidad de la solución, una vez conocida. Ese es el caso de la magia: partir una persona en dos, aparecer un conejo o adivinar una carta, una vez es conocido el truco el interés por explicarlo es una ilusión. La complejidad es entonces resultado de las posibilidades y limitaciones biológicas del observador. ¿Cuántos siglos tardo la humanidad para comprender y explicar correctamente (simple) el movimiento de los astros, en particular el de los planetas? Hoy esos conocimientos se imparten en la escuela primaria, al igual que muchos otros, sin sorprender a los niños.

Espejo y Reyes (2006) definen la complejidad como el número de distinciones o comportamientos relevantes seleccionados por un observador, es una capacidad fundamental de los seres humanos, no es una característica intrínseca de una situación. Nosotros distinguimos partes, relaciones y totalidades; entornos, sistemas y componentes; células, órganos y seres vivos.
La complejidad es complexus: lo que está tejido en conjunto, elementos con posibilidades múltiples de interconexión. La complejidad es dialéctica y da origen a la simplicidad, se constituye en paradoja de la observación; divide y suma, reduce e integra, separa y agrupa. En palabras de Luhmann "la complejidad es un estado de cosas autocondicionado, debido a que los elementos deben constituirse complejamente para fungir como unidad en el nivel superior de la formación de sistemas, y por lo tanto su capacidad de acoplamiento es limitada."

De esta manera, para Luhmann (1998:47), complejidad significa exigencia a seleccionar. Y exigencia a seleccionar significa contingencia, y contingencia significa riesgo. Cualquier estado de cosas complejo se basa en una selección de relaciones entre los elementos, los que a la vez, son utilizados para constituirse y conservarse. La selección sitúa y cualifica los elementos, aunque para estos fueran posibles otras relaciones.

Lo enredado, el desorden, el montón, lo incontable, la variedad y hasta la incertidumbre, expresan complejidad al observador, pero mediante análisis y síntesis dicha complejidad es reducida, comprendida y distinguible. Nuestras mentes, el conocimiento y en particular las distinciones de un observador en un contexto definen la complejidad o el número de estados posibles de un sistema. Por ejemplo, el discernimiento del mundo de hoy es el resultado de millones de años de evolución biológica y de la reducción de la complejidad gracias a la gran capacidad humana de construir artefactos para mejorar nuestra percepción. 
Luhmann (1998:48), comprende la complejidad como un fenómeno emergente, veamos:

"Por medio de la exigencia de selección y el condicionamiento de las selecciones, podemos explicar por qué de una capa inferior de unidades muy similares, como unos pocos tipos de átomos y de organismos humanos muy parecidos, se pueden formar sistemas muy distintos. La complejidad del mundo, de las especies y los géneros, la formación de los sistemas, se lleva a cabo mediante la reducción de la complejidad y gracias al condicionamiento de esta reducción. Solamente así se puede explicar que la duración de lo que luego funge como elemento, puede ser armonizado con la autogeneración del sistema. Con todo eso, la teoría abstracta de la racionalidad compleja ha sido llevada hasta el punto donde hay que conectarla con las explicaciones teóricas de la evolución y de los sistemas."

En conclusión, la complejidad no es un problema cuantitativo inconmensurable o de azar, es un problema de posibilidades de selección, de limitaciones biológicas y de conocimiento (manejo distinciones), incluso en ocasiones es un problema instrumental de cognición.

\section{DiNÁMICA Y PENSAMIENTO SISTÉMICO}

Peter Senge en La V disciplina y Joseph O'Connor y lan McDermott en su libro titulado Introducción al pensamiento sistémico, nos ofrecen herramientas para ejercer una mayor influencia en la propia vida. Puede utilizarse para hacer previsiones y prepararse de cara al futuro. Proporciona métodos más eficaces para afrontar los problemas y mejores estrategias de pensamiento y acción. Es la base de un razonamiento claro y una buena comunicación, una forma de profundizar y ampliar nuestro punto de vista. El pensamiento sistémico es un instrumento fundamental para auto-guiarse y dirigir a otros con eficacia.

El pensamiento sistémico es un reflexión en círculos más que en línea recta. Todas las partes de un sistema están conectadas directa o indirectamente de modo que al cambiar una de las partes el efecto se propaga a todas las demás que experimentan un cambio y a su vez afectando a la parte original. Cuando dos partes están conectadas, la influencia se transmite en las dos direcciones. La única forma de recibir la realimentación es por medio de nuestros sentidos. La mayoría de las veces la realimentación genera cadenas de causas y efectos en las que cada acción influye en la siguiente. Se debe tener en cuenta que sin realimentación no hay sistema. Una simple conversación es un proceso de retroalimentación circular. 
Figura No. 4. Ciclo de realimentación en la comunicación ${ }^{11}$

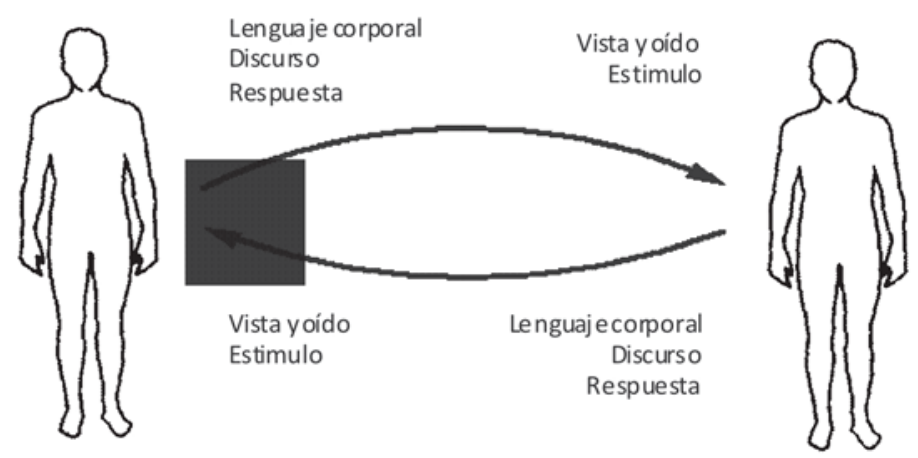

El punto es como aumentar las soluciones y disminuir las situaciones paralizantes o de asombro. Existen dos clases de realimentación estas son: la de refuerzo y la de compensación:

Realimentación de refuerzo: se presenta cuando los cambios registrados en todo el sistema se realimentan para amplificar el cambio original. Por ejemplo una bola de nieve es un claro ejemplo de realimentación de refuerzo, ya que esta cada vez que desciende por una colina, va adquiriendo mas nieve que se va adhiriendo a al bola original. Las siguiente grafica demuestra como la evolución en el ciclo se hace de forma prolongada y directamente proporcional a su tamaño y tiempo de evolución.

Un ejemplo de una situación reforzadora: un ejecutivo sobrecargado de trabajo que no consigue concentrarse en un proyecto. La falta de concentración le lleva al error y a tener que repetir la labor, con lo que aumenta la sobrecarga de trabajo. Figura 5.

Figura 5.

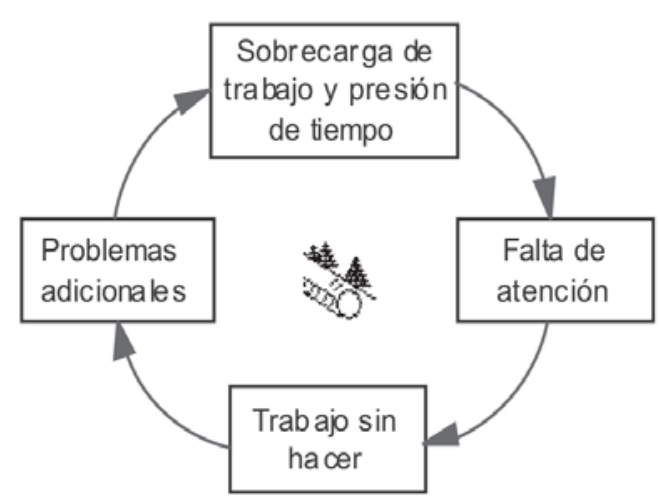

${ }^{11}$ O’Connor y Ian McDermott. Op. Cit. p. 54. 
Figura 6. El comportamiento en el tiempo

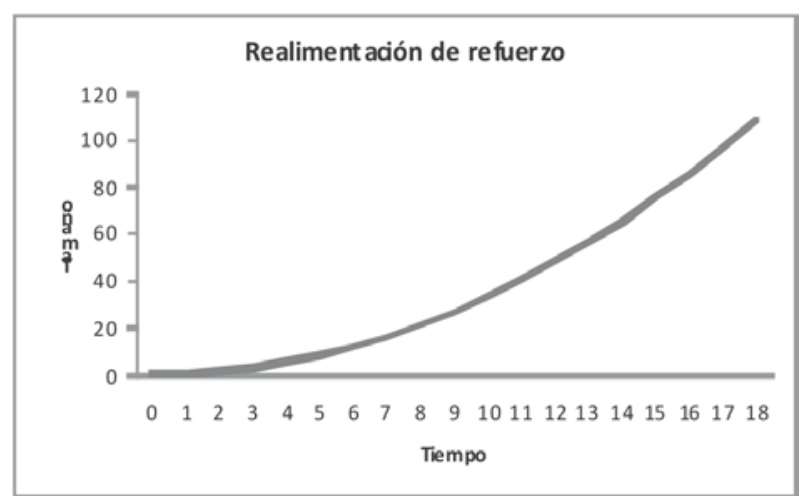

Realimentación de compensación o balance: ésta se da cuando los cambios registrados en todo el sistema se oponen al cambio original para amortiguar el efecto. Así los cambios en una parte del sistema generan cambios en el resto del sistema que reducen el sentido del cambio inicial.

Un ejemplo de situación de balance: Al inicio de una carrera es normal que las personas promedio empleen su mayor esfuerzo, al transcurrir el tiempo la fatiga hace reducir la velocidad y quizás por un buen tiempo se mantenga constante, si la carrera dura mucho tiempo el punto de equilibrio será cero velocidad. Figura 7.

Figura 7

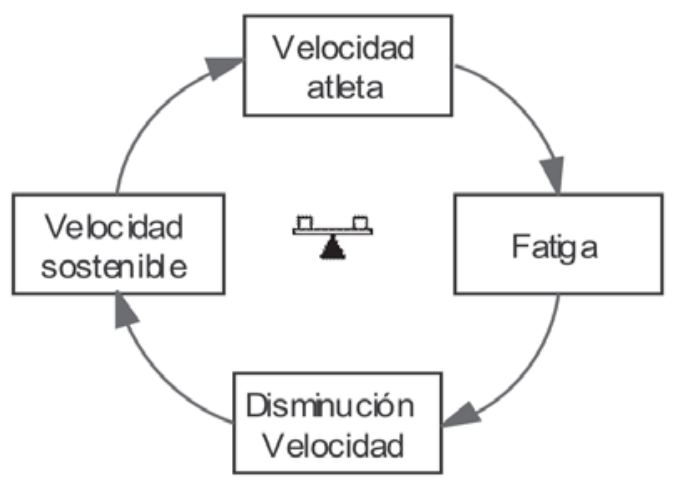

El comportamiento en el tiempo será, Figura 8:

Figura 8

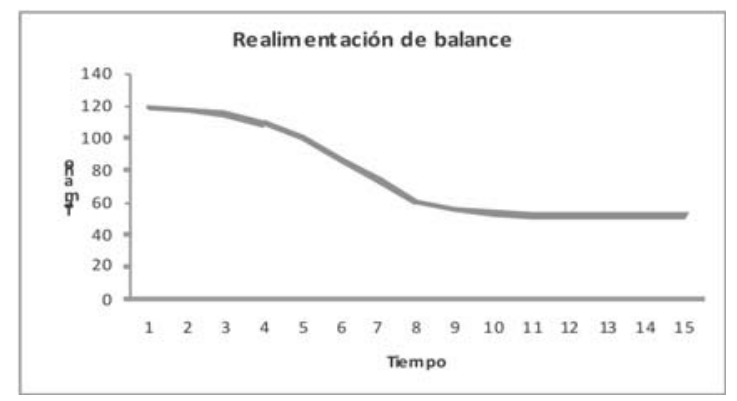


La mayoría de las veces la realimentación genera cadenas de causa y efecto en las que cada acción influye en la siguiente. Por ejemplo la sed nos hace beber y beber nos quita la sed. La causa del presente da lugar al efecto del futuro.

Cuando tenemos la esperanza de que vamos a superar algo nuestra energía y optimismo se ponen a nuestro favor y hay más probabilidades de que lo logremos. La pro alimentación crea premoniciones que se cumplen. Por ejemplo ¿Qué hace que la gente cuando se anuncia que va a escaseara algo? Compra la mercancía de que se trate por si acaso. Incluso compra más de lo habitual para prevenirse de la escasez proyectada de manera que se crea así la escasez prevista. ¿Qué ha causado alarma?

El pensamiento sistémico lo podemos relacionar con supuestos básicos que están detrás de cómo pensamos y resolvemos nuestros problemas. Nuestras estrategias, perspectivas, creencias, guías, ideas fijas y similares profundamente arraigadas en nosotros, que orientan nuestros actos constituyen "los modelos mentales". Modelos porque los construimos a partir de nuestra experiencia y mentales porque están en nuestra mente.

La principal característica del mundo es que no es lógico, es desordenado, incompleto y hasta ambiguo. Por eso se ha desarrollado la lógica difusa que trata el "quizá" o el "tal vez" ya que nuestras decisiones muy pocas veces son bien definidas. El pensamiento sistémico toma en cuenta además de la lógica, tres dimensiones cruciales más, el tiempo, la autoreferencia y la recursividad.
La lógica es atemporal y se basa en principios como, si esto, entonces aquello, es decir, causa y efecto. Pero a pesar de estas características la lógica no es lo mismo que causa y efecto, incluso es posible invertir la lógica, lo cual no es el caso de las cadenas de causa y efecto o diagramas de influencia.

En ese sentido el aporte de la física relativista es claro; el concepto de materia ampliado a energía y en la mecánica cuántica, el principio de incertidumbre de Heisenberg, el cual cala en la esencia del conocimiento y de la ciencia, "la relatividad de la información" y "el concepto de causalidad", al cual quiero referirme ahora: "... cuanto con mayor precisión se trate de medir la posición de la partícula, con menor exactitud se podrá medir su velocidad, y viceversa... ese limite no depende de la forma en que se trata de medir la posición o la velocidad de la partícula, o del tipo de partícula: el principio de incertidumbre de Heisenberg es una propiedad fundamental, ineludible, del mundo. [Por lo tanto,] tiene profundas implicaciones sobre el modo que tenemos que ver el mundo."12

El pensamiento sistémico nos acerca a estas situaciones, el análisis se centra en ciclos de realimentación, los círculos viciosos y virtuosos que nos permiten llegar una y otra vez al mismo punto de partida probablemente a otro nivel.

Al tener perspectivas diferentes ampliamos nuestros modelos mentales y los modelos mentales más abiertos nos llevan a ampliar más las perspectivas, con lo cual se forma un ciclo de refuerzo que amplia nuestra visión del mundo. Figura 9.

12 HAWKING, Stephen W. La historia del tiempo. Editorial crítica. España. 1988. p. 83 
Además de hacer que nuestra mente se comporte como un sistema de solucionar problemas debemos así mismo darle las pautas para que actuemos y pensemos de forma global. Por ejemplo: A veces actuamos como si la tierra fuera plana, simplificamos demasiado y no vemos la globalidad. Una línea recta forma parte de un arco de un círculo. Parece plana porque nuestra visión es limitada. Una línea recta es la unión de puntos. Si vemos

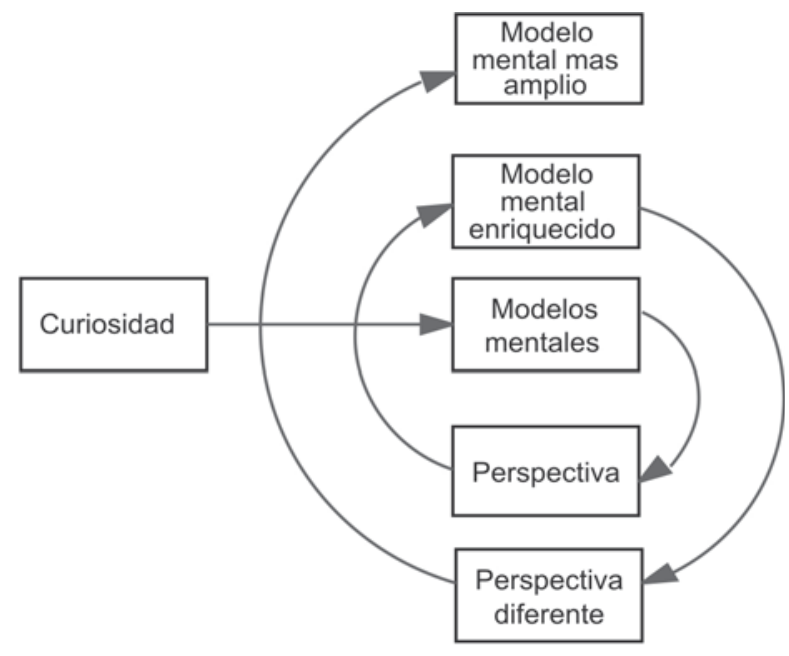
el sistema vemos la línea recta.

Y ya para ultimar, el pensamiento sistémico nos permite elaborar una representación gráfica de nuestras observaciones, posibilidades, interpretaciones y conclusiones. Dibujar las conexiones y las interacciones, de manera que veamos el sistema y su dinámica. Dibujar nuevas conexiones e interconexiones. Si representamos los procesos de nuestro propio pensamiento, obtendremos una escritura de nuestros propios modelos mentales. En ese diagrama podemos ver nuestra situación, como se ha ido formando y los supuestos en los cuales se basa. Para la elaboración de estos gráficos se deben tener en cuenta una serie de pautas:

1. El personaje central es el evento o situación. Cada cual debe elaborar la representación desde su experiencia y su punto de vista.

2. La representación debe elaborarse con un objetivo en mente, ¿qué es lo que se pretende comprender?

3. El comienzo puede fijarse donde uno quiera.
4. Hay que incluir los sucesos, lo que uno observa, escucha y siente. Ser especialmente significativos, para identificar el patrón.

5. Es necesario establecer un límite del sistema, incluyendo el marco temporal y las personas que forman el sistema, según sea el objetivo.

6. Utilizaremos únicamente elementos que puedan aumentar o disminuir, es decir, que puedan cambiar al ejercer sobre ellos alguna influencia. Si se desea utilizar algo fijo, debemos preguntarnos, ¿que me aporta?

Existen una serie de estructuras que orientan conductas en la identificación y disolución de los problemas, el sistema manifiesta una dinámica observable a manera de patrón. A continuación presentan los principales arquetipos. 


\begin{tabular}{|c|c|}
\hline $\begin{array}{l}\text { Ciclo de refuerzo. La figura muestra un proceso } \\
\text { de realimentación reforzada. Si una empresa tiene } \\
\text { éxito con una estrategia tiende a repetirla y si } \\
\text { nuevamente tiene éxito seguramente la aplicara } \\
\text { de nuevo. Por en una persona que recibe un } \\
\text { llamado de atención puede caer en depresión y } \\
\text { seguramente recibirá uno nuevo. }\end{array}$ & $\frac{1}{B}$ \\
\hline $\begin{array}{l}\text { Ciclo de balance. Contrarresta el crecimiento } \\
\text { y conduce al equilibrio. Los procesos } \\
\text { compensadores son difíciles de administrar } \\
\text { porque están implícitos y no suelen observarse } \\
\text { en la fase de planeación. La realimentación es } \\
\text { compensadora y constantemente debe valorarse } \\
\text { la brecha tomado acciones convenientes. }\end{array}$ & $\frac{a}{2}$ \\
\hline $\begin{array}{l}\text { Límites del crecimiento. El ciclo crecimiento } \\
\text { se frena, se obtienen cada vez menos resultados } \\
\text { con el mismo esfuerzo. El ciclo de refuerzo es } \\
\text { anulado por uno de balance. ¿Qué hacer para } \\
\text { aumentar el desempeño o lograr los resultados } \\
\text { esperados del sistema? Identificar la restricción y } \\
\text { reforzarla o anularla. No todo lo que brilla es oro. }\end{array}$ & 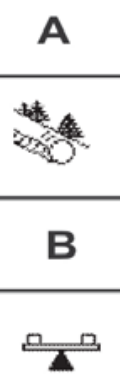 \\
\hline $\begin{array}{l}\text { Erosión de metas. El esfuerzo es continuo, pero } \\
\text { hay muy pocas mejoras desde el principio. Los } \\
\text { objetivos van en ascenso o se fijan demasiado } \\
\text { altos. El rendimiento no deja de disminuir. Nos } \\
\text { vemos obligados a estar en conflicto con otros } \\
\text { para nuestro perjuicio. Enfrentamiento man- } \\
\text { tenido. Es clave Identificar las metas iníciales } \\
\text { y posibles puntos de referencia externos para } \\
\text { las metas de la organización, pueden evitar la } \\
\text { erosión de dichas metas. }\end{array}$ & $\frac{n}{1}$ \\
\hline
\end{tabular}




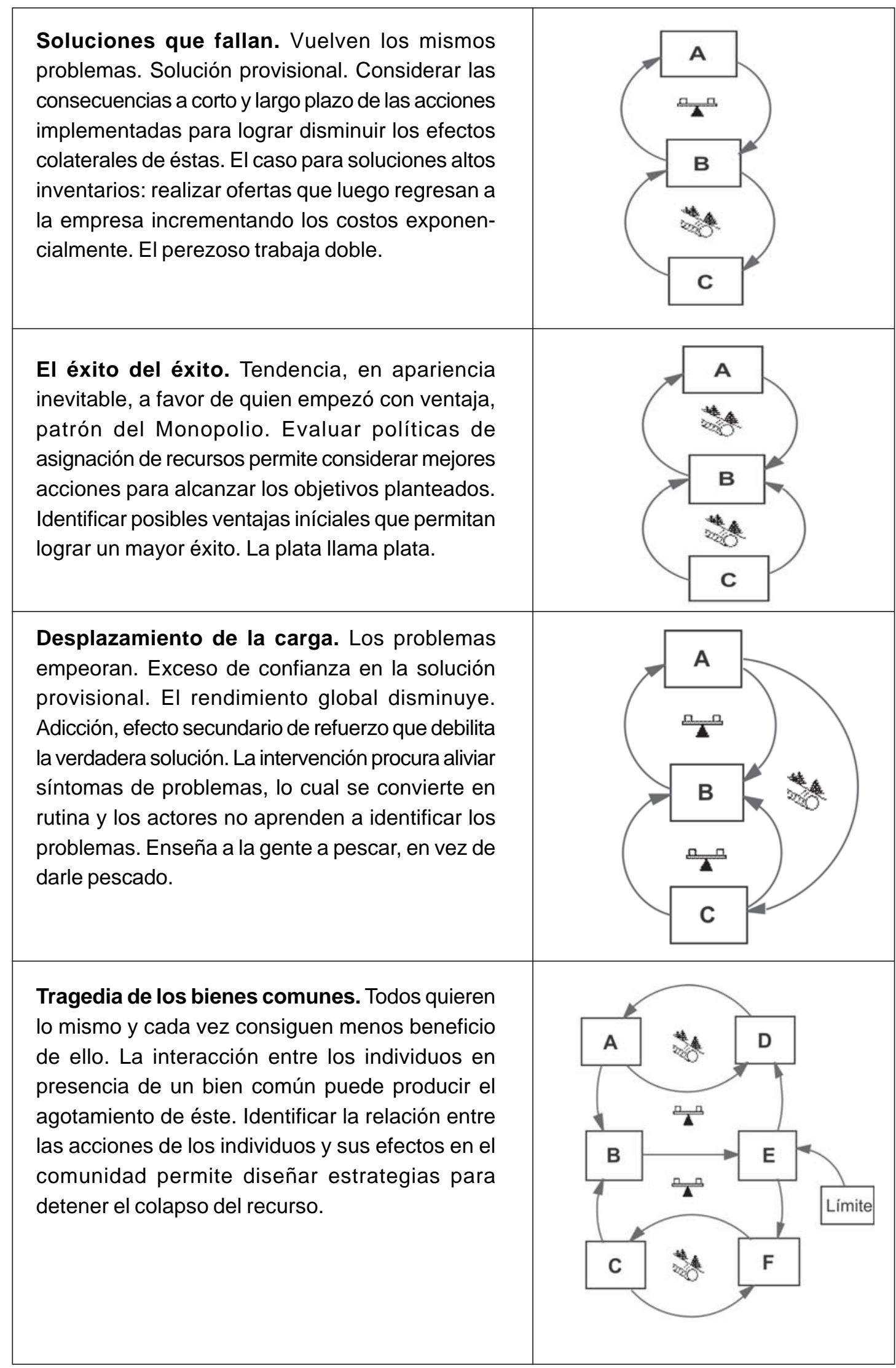




\section{ESTRUCTURAS AUTOPOIETICAS}

Un sistema que produce los elementos, procedimientos o moléculas a partir de sus mismos elementos, procedimientos o moléculas, nos recuerda la paradoja ¿qué fue primero el huevo o la gallina? o ¿quién creo al universo?, Dios, y ¿quién creo a Dios?. Esta estructura circular causal, en principio paradójica, es la base de la dinámica de sistemas, así como el principio de Heisengber es el punto de partida de la teoría de la incertidumbre y la observación moderna.

Revisemos algunas estructuras, operaciones y conductas observables en los sistemas biológicos que propician analogías y metáforas para representar los sistemas sociales, en particular las organizaciones empresariales. Es el caso de la organización molecular representada en la figura 10.

Figura 10

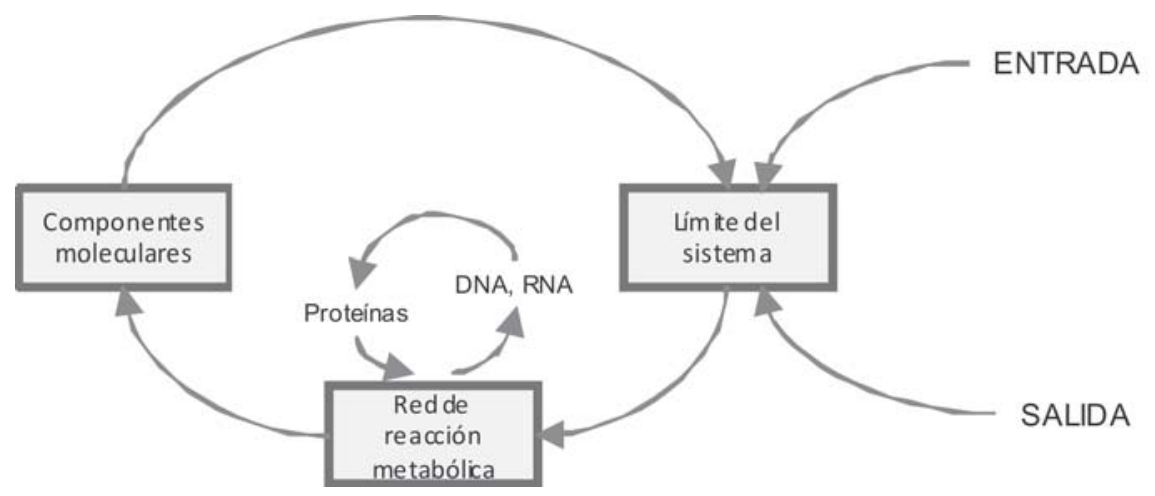

La circularidad del sí mismo en la organización autopoiética: En sus relaciones operacionales, los componentes moleculares determinan una red dinámicamente organizada y enlazada de transformación (metabolismo), que produce los componentes moleculares de la membrana, lo que, a su vez permite la operación de la red, y así sucesivamente. En nuestro mundo biológico, todo el sistema de reacciones está regulado por los ácidos nucleídos, como aparece en la figura 10, Varela (2002:34).

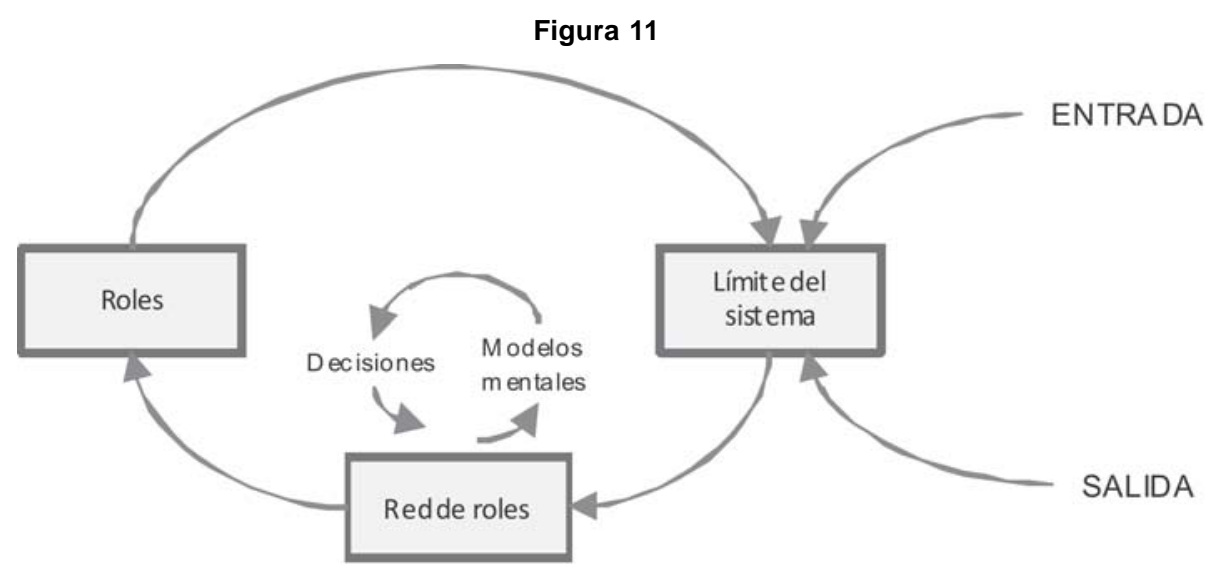


La decisiones moldean la organización y a sus miembros, ellos forjan su modelos mentales y estos a su vez generan nuevas decisiones. Así la red de roles genera o elimina roles delimitando el sistema, el cual demanda insumos y oferta productos. Figura 11.

La idea de organismo implica una dialéctica complicada: un sistema viviente se estructura a sí mismo como una entidad distinta a su medioambiente mediante un proceso que genera, a través de este mismo proceso, un mundo adecuado para él.

Utilizo el término dialéctica para describir propiedades que se relacionan de manera que "... una cosa no puede existir sin la otra, que una adquiere sus propiedades de su relación con la otra, que las propiedades de ambas se desarrollan como consecuencia de sus interacciones", Varela (2002:77). Es el caso de la célula, membrana y fluidos internos.

La relación entre organismo y el sí mismo (self) resulta ser la imbricación de dos dialécticas distintas: una ligada al mecanismo de la identidad, la otra unida al modo de relacionarse con el mundo. Varela (2002:78).

Esta configuración es determinante: las operaciones conforman círculo cerrado, motivo por el cual los productos se encuentran en el mismo plano que los proceso de producción. Dentro de esta organización pierden sentido las diferenciaciones usuales entre productor y producto, entre comienzo y final o entre input y output. Varela (2002:373), figura 12.

Figura 12

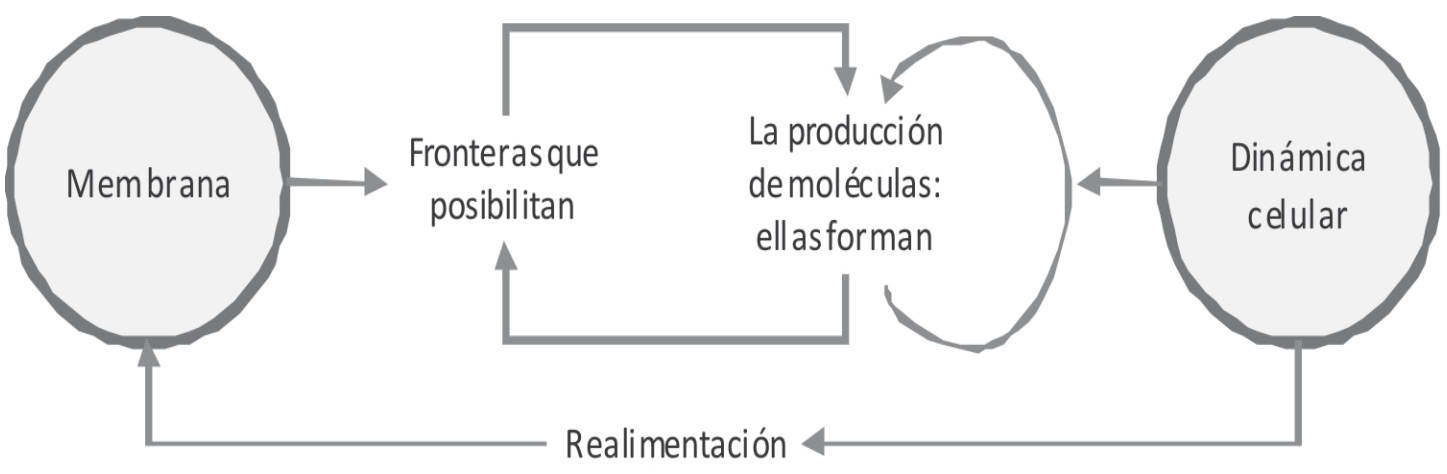

Para el caso del análisis de las empresas cuando se conforman definen su frontera y mercado meta, este puede ser difuso en principio, se ubica geográficamente y se destinan recursos sean del propio hogar o independientes para las operaciones del negocio. Se gestan procedimientos y operaciones empíricas, que luego maduran, se formalizan y estandarizan, se instituyen reglas y procedimientos para los procesos y procedimientos, generando una estructuración de la estructura, una dinámica de producción operacional interna, que modifica y mantiene la empresa. Los ciclo tienen retardos y su dinámica pude ir en distintas direcciones, reforzando o balanceando, formando ciclos virtuosos o viciosos. Figura 13. 
Figura 13

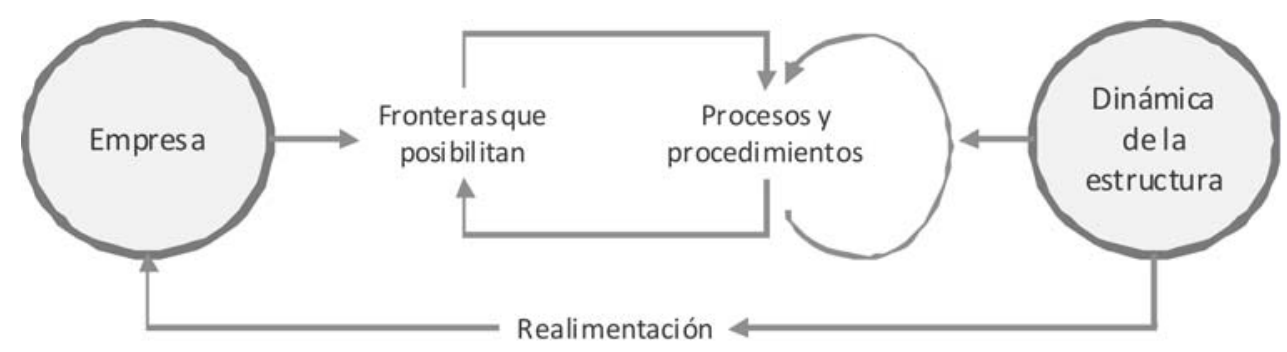

Para finalizar, veamos la dinámica del proceso de cambio humano: las creencias mantenidas por los humanos determinan las decisiones que toman, y éstas, a su turno, estructuran los cambios del paisaje humano. North (2007:45). Figura No.14.

Figura 14

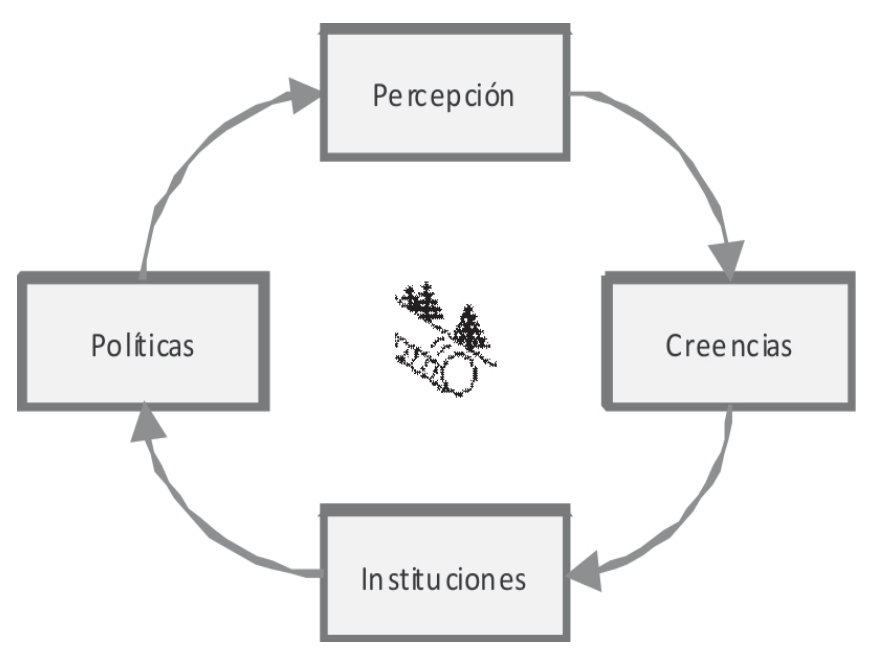

Los interesantes problemas que exigen solución provienen de la interacción de los seres humanos en ámbitos económicos, sociales y políticos donde los actores cuentan con una información imperfecta y la retroalimentación de sus actos es también imperfecta... La información y la retroalimentación imperfectas subyacen al carácter generalizado de la incertidumbre, North (2007:46).

El cambio económico consiste en el cambio material y físico del bienestar de los humanos. Esto es concebido de manera tanto tangible como intangible -el stock de conocimiento es un determinante fundamental en estos aspectos. Indica que el stock de conocimiento, instituciones y factores demográficos determinan el proceso de cambio económico, Dyner (2007). 


\section{CONCLUSIONES}

Es urgente realizar investigaciones empíricas al interior de las organizaciones, reconociendo la perspectiva aquí presentada como eje de análisis. La discusión está en el punto más álgido y por tanto requiere de evidencias, ejemplares e instrumentos que permitan orientar de manera distinta la gestión del cambio en las organizaciones. No solo al interior, las relaciones con el entorno en términos de captura, procesamiento y producción de conocimiento, sea para la organización, en la cadena de abastecimiento o en un cluster se convierten en problema de investigación.

El análisis de las organizaciones desde la teoría general de sistemas moderna, en particular desde la sistemología social de Luhmann es un reto para los administradores y profesionales de las ciencias empresariales, estamos en una época de grandes transiciones y para enfrentarlas se requieren de paradigmas mas robustos que desdoblen la complejidad y se aproximen a la certeza cognitiva.

La investigación intra e inter-disciplinaria se constituyen en una fuente de opciones distintas y nuevas de análisis, percepción y acción. Los feudos académicos, los celos profesionales y las torres de marfil son prácticas anacrónicas y sin sentido.

La teoría de sistemas, el pensamiento y la dinámica de sistemas son campos distintos de profundización con herramientas variadas de análisis, sin embargo, están imbricadas de tal manera que conforma una unidad, una metodología y un paradigma para comprender y transformar la "realidad", sea la que sea, este donde este.

Finalmente se requieren espacios académicos en los que el debate se intensifique, redes de investigadores y grupos que compartan abiertamente sus técnicas, instrumentos y logros. Invito a los holistas y a los no, a escribir para rehacer un movimiento pedagógico y de acción sistémica. 


\section{BIBLIOGRAFÍA}

ANDRADE, Sosa, Hugo, DYNER, Isaac y Otros, (2001). Pensamiento Sistemático: Diversidad en búsqueda de Unidad. Ediciones Universidad Industrial de Santander. Bucaramanga.

ASHBY, Ross (1977). Introducción a la cibernética. Edición Impulso Extensión Editorial de Libreros Mexicanos, S.A. EDIAPSA. México.

Bacherlard, Gaston (1973). El Compromiso Racionalista. Siglo XXI Editores, 3 a Edición, México.

BEER, Stafford (1982). Decisión y control. El significado de la investigación de operaciones y la administración cibernética. Fondo de Cultura Económica, México.

BEER, Stafford (1988). The managerial Cybernetics of Organizations. "Diagnosing the system for Organizations" John Wiley \& Son. New York.

BERTALANFFY, Ludwig von (1976). Teoría general de los sistemas. Fondo de cultura económica. Bogotá, Colombia.

CAPRA, Fritjof (2006). La trama de la vida. Editorial Anagrama. Sexta edición. España.

DYNER, Isaac (2007). Dinámica de sistemas para la transformación de las instituciones, el cambio económico y el desarrollo social. V Encuentro Colombiano de dinámica de sistemas. Medellín, Colombia.

ESCANDELL Vidal M. Victoria (1996). Introducción a la pragmática, Ariel Lingüística, Barcelona.

ESPEJO Raúl (2002). Systems and the Information Society: Requisite Organisations and Problem Solving. University of Lincoln, UK. October. http://itsy.co.uk/archive/sisn/Out/SisRops.pdf. Consultado 12 febrero de 2006.

ESPEJO Raúl, SCHUHMANN Werner \& others. (1996). Organizational Transformation and Learning. John Wiley. England.

FLORES, Fernando (1996a). Creando organizaciones para el futuro. Chile: Dolmen Ediciones.

FLORES, Fernando (1996b). Inventando la empresa del Siglo XXI. Chile: Dolmen ediciones S.A.

FOERSTER, Heinz von. (1996). Las semillas de la cibernética. Editorial Gedisa. España.

FORRESTER, Jay, W. Dinámica Industrial. Ed. Ateneo, 1981, Argentina.

HAWKING, Stephen W (1988). La historia del tiempo. Editorial crítica. España. http://www.epsilones.com/paginas/i-figurasimp.html\#figimp-ambiguedadanimal http://www.sintesys.cl/complexus/revista2/articulos2/leonardo\%20lavanderos.pdf. 
JOHNSON, Steven. Sistemas emergentes. Fondo de cultura económica. México, 2001.

LAVANDEROS L. y MALPARTIDAA., (2005). Teoría relacional de la comunicación como proceso eco_semio_autopoietico. Complexus. Vol $1 \mathrm{~N}^{0} 2$, pp. 45-86. http://www.sintesys.cl/complexus/ revista2/articulos2/leonardo\%20lavanderos.pdf.

LLINAS, Rodolfo. El cerebro y el mito del yo: El papel de las neuronas en el pensamiento y el comportamiento humanos. Editorial Norma, Bogotá. 2005.

LUHMANN, Niklas (1997). Organización y Decisión. Autopoiesis, acción y entendimiento comunicativo. Editorial Anthropos, España.

LUHMANN, Niklas (1998). Sistemas Sociales. Lineamientos para una teoría general. Editorial Anthropos, España.

MATURANA, H. \& VARELA, F. (1987). El Árbol de Conocimiento: Las Raíces Biológicas de Comprensión Humana. Boston: La Nueva Ciencia de la Biblioteca.

MATURANA Humberto (1997). La realidad, ¿Objetiva o construida? Tomo I, Anthropos, Barcelona.

MEJÍA D., Andrés y DÍAZ, Gloria Maritza (2006). Tipos de arcos y hacia dónde disparan: Sobre la naturaleza y posibilidades de los arquetipos. Universidad de Los Andes. IV congreso Latinoamericano de Dinámica de sistemas. Cancún, México.

MORGAN, Gareth (1991). Imágenes de la Organización. Ed. Alfaomega México.

MORIN, Edgar (1981). El Método tomo I, "La naturaleza de la naturaleza", Cátedra, Madrid.

MORIN, Edgar (1992). El método III. El conocimiento del conocimiento, Madrid, Cátedra..

NORTH, Douglass (2007). Para entender el proceso de cambio económica. Editorial Norma y Uniandes. Bogotá, Colombia.

O’CONNOR Joseph y McDERMOTT, Ian (2002). Introducción al pensamiento sistémico, Ediciones Urano. España.

OCAMPO, Eduardo (2007). Cap. 2. Elementos de gestión organizacional, en el libro administración, diseño y modelamiento de cadenas de abastecimiento. VELASQUEZ, ANDRÉS y otros. Universidad Autónoma de Colombia. En imprenta, Bogotá.

PINTOS, Juan Luis. La nueva plausibilidad: la observación de segundo orden en Niklas Luhmann. Consultado 20 de septiembre de 2007. http://web.usc.es/ jlpintos/articulos/

REYES, Alfonso and Kaye Rupert (2002). Exploring the relationship between distributed leadership and organisational learning: A case of a primary school in London. BELMAS 2002. 20 - 22 September 2002, Aston, Birmingham, England. http://www.shu.ac.uk/bemas/conferencepapers2002.html.

REYES, Alfonso, (2005). Material digital del Curso: Aprendizaje Organizacional. Maestría en Ingeniería Industrial, Universidad de los Andes. Colombia. 
SALAZAR, Diego. Distinciones y Comunicaciones. Hacia una teoría social hermenéutica y constructivista en arqueología. Cinta de Moebio No.2. Diciembre de 1997. Facultad de Ciencias Sociales. Universidad de Chile. http://www.moebio.uchile.cl/02/frprin04.htm.

SCHVARSTEIN, Leonardo (2001). Psicología social de las organizaciones. Paidos, Buenos Aires.

SENGE, Peter M. (1990). La Quinta Disciplina. GRANICA. Barcelona, España.

SENGE, Peter \& otros, (2000). La Danza del Cambio. Editorial Norma. Colombia.

SUPPE, Frederick (1979). La Estructura de las Teorías Científicas. Editora Nacional, Madrid, España.

VARELA, Francisco (2002). El fenómeno de la vida. Ediciones Dolme. España.

VELÁSQUEZ, Andrés T. (2006). Diseño de organizaciones para la producción de conocimiento. Revista EAN, Escuela de Administración de Negocios. No. 58, enero-abril. p. 5-26.

VELÁSQUEZ, Andrés T. (2005). Análisis Situacional, Intervención y Aprendizaje Organizacional. Revista EAN, Escuela de Administración de Negocios., No. 53 Enero - Abril, Bogotá, Colombia. pp. 52-71.

Vensim PLE and Vensim PLE Plus version 4.0d. 1988-2000. Se utilizó para los dibujos de ciclos.

ZARAMA, R. and REYES, A. (1998) The Process of Embodying Distinctions: A Reconstruction of the Process of Learning. In Cybernetics and Human Knowing: A Journal of Second Order Cybernetics, Cyber-Semiotics and Autopoiesis, Vol. 5, No. 3, Oct. 1998.

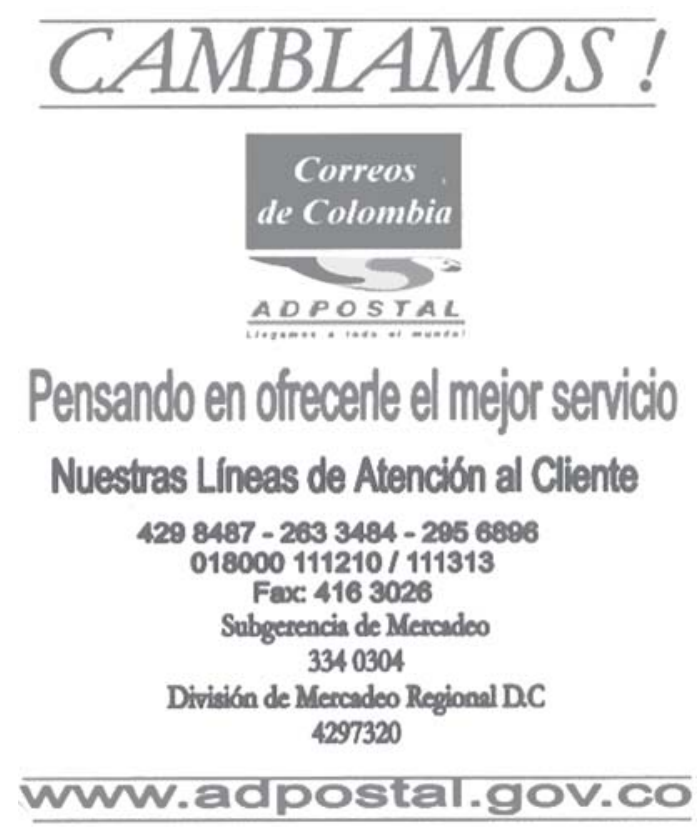



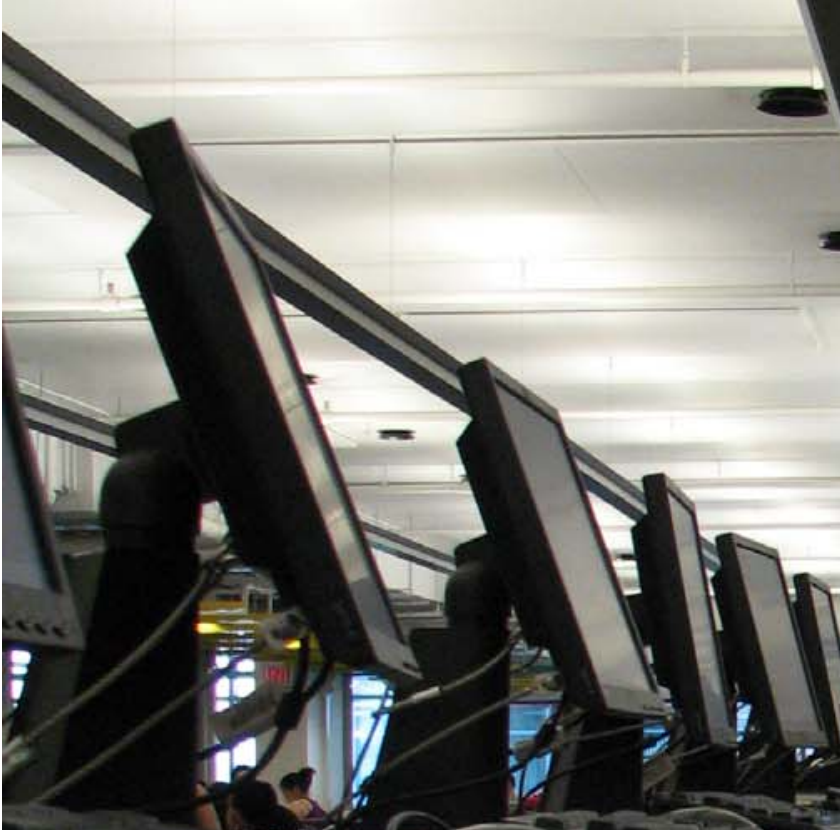

(4)

bit?
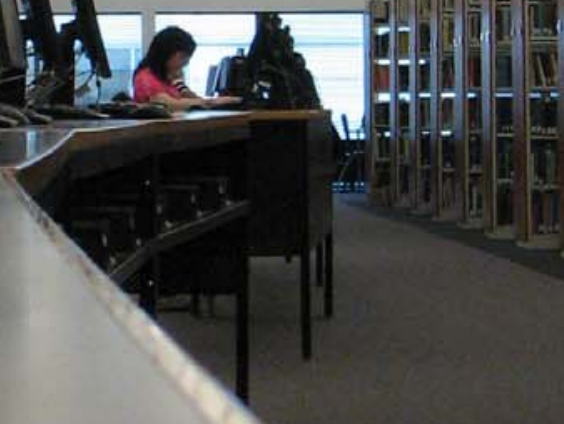